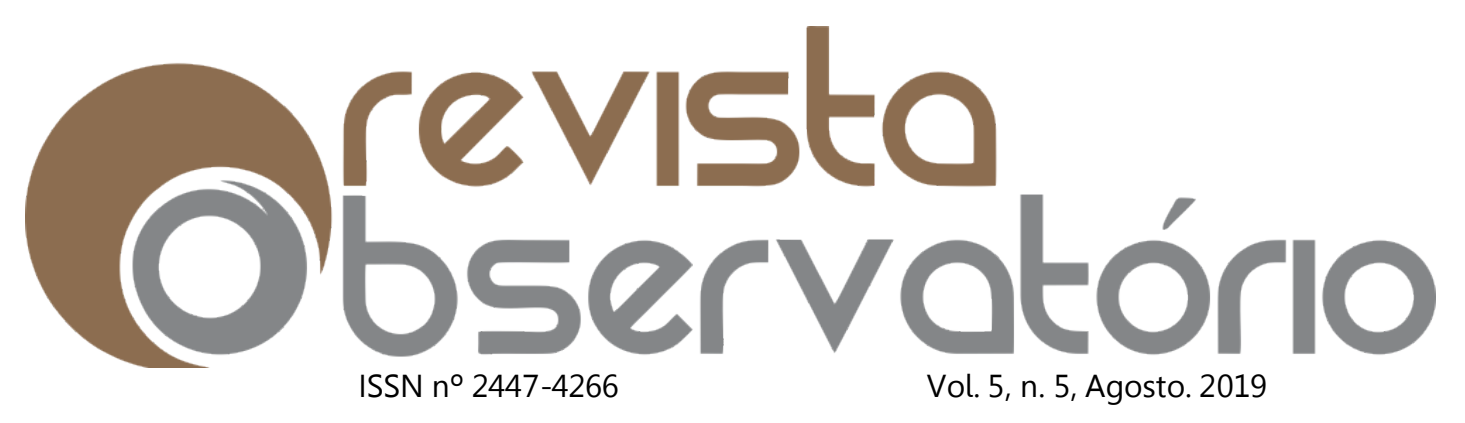

DOI: http://dx.doi.org/10.20873/uft.2447-4266.2019v5n5p937

\section{TECNOLOGIAS DIGITAIS E \\ EDUCAÇÃO: impactos e \\ desafios para uma nova \\ configuração de subjetividade}

\section{Elaine Moraes Santos ${ }^{1}$ \\ Luiz Antonio Calmon Nabuco Lastória²}

\title{
RESUMO
}

Este trabalho pretende problematizar à luz da Teoria Crítica da Sociedade os impactos e desafios que o atual regime de vida apoiado no uso das tecnologias digitais traz para o campo da educação, com o intuito de que esta investigação possibilite um novo olhar metodológico sobre a utilização destes recursos em prol de um ambiente escolar que reconecte o espaço alargado entre os tradicionais moldes de ensino e a nova subjetividade e identidade contemporânea do alunado.

PALAVRAS-CHAVE: Tecnologias digitais; Educação; Impactos; subjetividade

\footnotetext{
${ }^{1}$ Doutorado em Educação pela Universidade de São Paulo (USP), mestrado em Educação Escolar pela Unesp de Araraquara e graduação em psicologia pela Universidade Metodista de Piracicaba (UNIMEP). E-mail: elainecms@usp.br.

${ }^{2}$ Livre Docente em Psicologia Social. Doutorado em Psicologia Escolar e do Desenvolvimento Humano pela Universidade de São Paulo. mestrado em Psicologia Social pela Pontifícia Universidade Católica de São Paulo (1992). Realizou estágios pós-doutorais junto a J. W. Goethe Universität, Frankfurt am Main, e junto a Universitat des les Illes Balears, Palma de Mallorca - ES.E-mail: lacalmon@uol.com.br.
} 


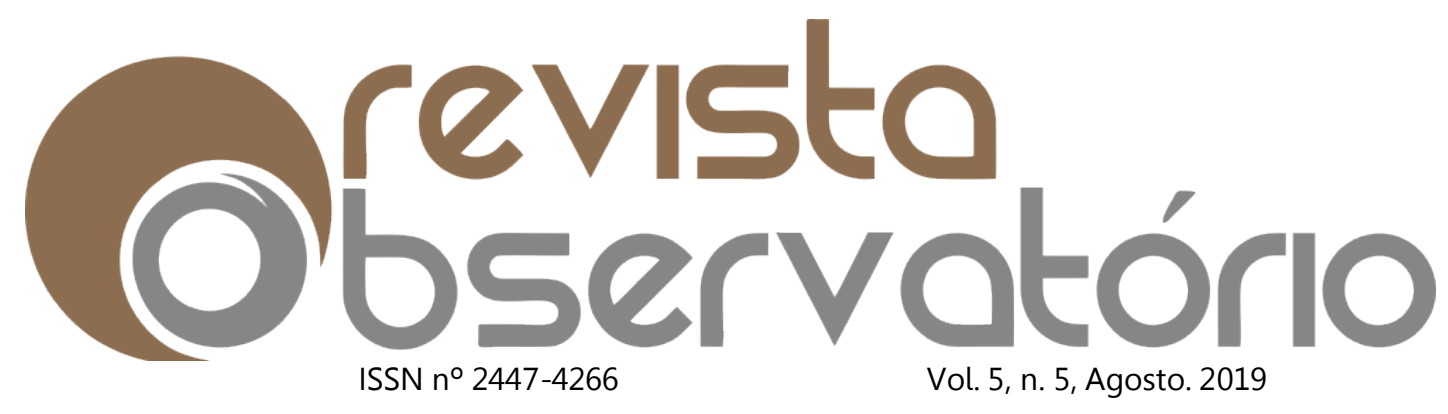

DOI: http://dx.doi.org/10.20873/uft.2447-4266.2019v5n5p937

\section{ABSTRACT}

This work is designed to problematize in the light of the Critical Theory of the Society of the impacts and challenges that the current regime of life supported without the use of the digital technologies brings to the field of education, with the intention that this investigation allows a new methodological look on one of these resources in favor of a school environment that covers the wide space between the translators of teaching and new subjectivity and contemporary identity of the student.

KEYWORDS: Digital technologies; Education; Impacts; subjectivity

\section{RESUMEN}

Este trabajo pretende problematizar a la luz de la Teoría Crítica de la Sociedad los impactos y desafíos que el actual régimen de vida apoyado en el uso de las tecnologías digitales trae al campo de la educación, con el propósito de que esta investigación posibilite una nueva mirada metodológica sobre la utilización de éstos recursos en pro de un ambiente escolar que reconecte el espacio ampliado entre los tradicionales moldes de enseñanza y la nueva subjetividad e identidad contemporánea del alumnado.

PALABRAS CLAVE: Tecnologías digitales; Educación; Impactos; subjetividad.

Recebido em: 06.03.2019. Aceito em: 12.06.2019. Publicado em: 01.08.2019. 


\section{Observatório \\ ISSN n 2447-4266 Vol. 5, n. 5, Agosto. 2019}

DOI: http://dx.doi.org/10.20873/uft.2447-4266.2019v5n5p983

A partir da Revolução Industrial ${ }^{3}$, o desenvolvimento tecnológico conheceu uma aceleração crescente em favor de um novo modo de produção que se estabeleceu: o capitalismo. A rede de computadores e a internet, que a princípio surgiram para atender demandas militares durante o período da Guerra Fria (1969) ${ }^{4}$, em pouco tempo ultrapassou as fronteiras oficiais bélicas para se tornar acessível no cotidiano da população. Ao deslizar velozmente como um novo modelo de comunicação e informação, sua utilização passou a servir um novo campo de guerra, constituído sob um território de tensão que, de um lado, encontram-se os alunos que assumem uma identidade e subjetividade contemporânea permeada quase que integralmente, por meio destes objetos ${ }^{5} \mathrm{e}$, de outro, o contexto escolar, enquanto uma categoria, muitas vezes, considerada retrógada e obsoleta frente aos atrativos recursos digitais. O imperativo social de mobilidade entra em choque com um espaço delimitado por paredes, grades, fechaduras, intervalos regulares de tempo, com limites e regulamentos estritos e enrijecidos por uma tradição pedagógica constituída sob a perspectiva de uma identidade que muito se diferencia da contemporânea (SIBILIA, 2012, p.28).

Diante dos cativantes recursos audiovisuais, canais interativos e navegadores virtuais, o modelo tradicional escolar passou a ser visto como algo desestimulante. A escola, ainda presa a lugares e tempo determinado, passa a ser questionada em relação as suas metodologias de ensino e eficácia no que tange

\footnotetext{
${ }^{3}$ Dentre o conjunto de mudanças que ocorreram na Europa durante o período da Revolução industrial (séculos XVIII e XIX), uma das principais foi a substituição do trabalho artesanal pelo assalariado com o uso de máquinas.

${ }^{4}$ As forças armadas norte-americanas criaram este mecanismo de comunicação em rede como uma garantia de segurança, caso viessem a sofrer ataques que dificultassem o acesso aos meios convencionais de telecomunicações. Já a partir de 1970, além de utilizada para fins militares, a internet expandiu-se para outros meios sociais, sobretudo acadêmicos.

${ }^{5}$ Os objetivos englobam toda rede de aparelhos digitais disponíveis, incluindo: laptops, smarthphone, e-readers e tablets.
} 


\section{Observisto \\ ISSN n² 2447-4266 \\ Vol. 5, n. 5, Agosto. 2019}

DOI: http://dx.doi.org/10.20873/uft.2447-4266.2019v5n5p983

à aprendizagem, restando dúvidas sobre seu papel na sociedade. Na tentativa de atenuar a distância entre a instituição escolar e as novas prerrogativas interacionais, algumas iniciativas educativas têm buscado, à seu modo, enfrentar o desmoronamento da velha escola, a partir de estratégias que se utilizem destes dispositivos para atrair e seduzir novamente o alunado. Porém, a ausência de uma perspectiva crítica sobre estes aparatos, na maioria das vezes, produz apenas uma aprendizagem instrumental e técnica, incapaz de produzir um efeito pedagógico mais amplo, em suas dimensões históricas, psicológicas e sociais. Por isso, não compreender a complexidade apresentada por estes recursos na constituição da identidade e subjetividade dos alunos, pode se apresentar desastroso diante de um olhar educativo ainda preso a antigos modos de ser e formar o alunado.

Para o sociólogo Stuart Hall, um dos maiores estudiosos contemporâneos sobre a concepção de indivíduo cultural pós-moderno, a noção de identidade ${ }^{7}$ teve três diferentes concepções ao longo da história: a primeira, refere-se ao sujeito do Iluminismo, baseado numa percepção humana do século XVIII, que estava ligada a uma ideia de centralidade e razão. Esta identidade estaria voltada à noção de particularidade e de individuação, em que o "eu" é o que representa, de fato, a identidade, desde o nascimento até a morte. A segunda forma seria o sujeito sociológico, que reflete a crescente complexidade do mundo moderno e suas relações. A identidade nessa concepção sociológica, passa a sofrer um processo de descentramento do eu para que se possa considerar também o outro, que envolve as relações sociais, os grupos e a sociedade de modo geral. A

\footnotetext{
${ }^{6}$ O sociólogo jamaicano Stuart Hall $(1932$ / 2014) foi um dos fundadores dos Estudos Culturais britânicos, recebendo a influência de pensadores como: Marx, Gramsci, Althusser, VolosinovBakhtin, Lacan, Derrida, Foucault, Laclau e Mouffe e outros.

7 In: HALL, S. Identidades Culturais na Pós-Modernidade. Tradução de Tomaz Tadeu da Silva; Guacira Lopes Louro. 11. ed. Rio de Janeiro: DP\&A, 2006.
} 


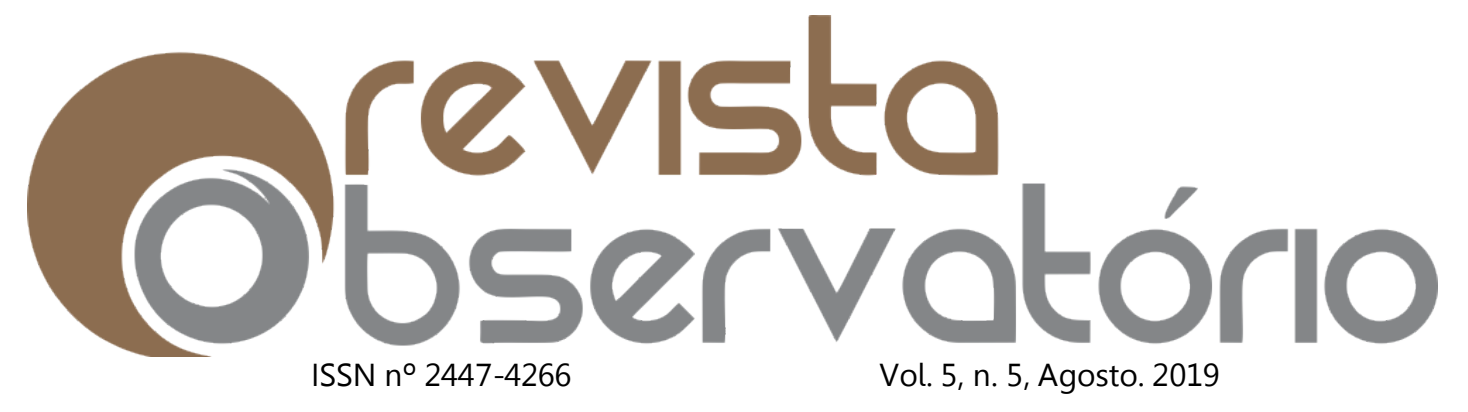

DOI: http://dx.doi.org/10.20873/uft.2447-4266.2019v5n5p983

identidade passa a ser entendida como um processo que se forma a partir das interações entre os indivíduos e as instituições que o representam. Já a terceira forma, seria o sujeito pós-moderno, que emerge de uma crise em relação a este sujeito iluminista e sociológico, que outrora se apresentava como unificado, estável e que está se tornando cada vez mais fragmentado, incompleto e contraditório. Para o autor, no séc. XXI, devido ao avanço dos meios de comunicação digital e de massa, as identidades são cada vez mais transnacionais e o sujeito é confrontado com uma imensidão desconcertante de identidades possíveis.

Neste sentido, para que a escola consiga superar a crise entre um novo regime de vida apoiado nas tecnologias digitais e os antigos moldes instrumentais analógicos da sala de aula, como: o giz, o quadro-negro, os boletins, os horários fixos e carteiras alinhadas é preciso levar em consideração os elementos que tem constituído e modificado a subjetividade dos alunos que apresentam no comportamento os efeitos de uma transição que revela um novo modo de ser e estar no mundo e que, na maior parte das vezes, não são compatíveis com o modelo tradicional de ensino e suas práticas. (SIBILIA 2012, p.52).

Para abordar uma perspectiva crítica e psicológica de como essas mudanças vem afetando as subjetividades contemporâneas, gostaria de apresentar alguns estudos e resultados apontados pela neurobiologia. Nicholas Caar $(2011)^{8}$, traz um interessante ensaio entre a história da literatura e da escrita, discutindo com propriedade os efeitos da tecnologia no âmbito da memória e do cérebro. O autor relata que em 2008, foi conduzido um experimento que mostrou modificações cerebrais em pessoas que usam com frequência a internet.

\footnotetext{
8 In: Caar, Nicholas. A geração superficial: o que a internet está fazendo com os nossos cérebros. Tradução de M. G. F. Friaça. Rio de Janeiro: Ed: Agir, 2011. 


\section{Observatório \\ ISSN n 2447-4266 Vol. 5, n. 5, Agosto. 2019}

DOI: http://dx.doi.org/10.20873/uft.2447-4266.2019v5n5p983

Para esse estudo, foram recrutadas 24 pessoas, dentre as quais metade eram usuários constantes da web e os demais não. E enquanto os voluntários realizavam buscas no Google ${ }^{9}$, seus cérebros eram escaneados. Os resultados mostraram que os sujeitos que já tinham um domínio maior com o computador usavam uma área específica na parte frontal esquerda do cérebro, conhecido como o córtex dorsolateral pré-frontal, enquanto que os demais exibiam uma atividade mínima dessa área. Em um segundo momento do experimento, os testes se repetiram por seis dias e, nesse intervalo, os pesquisadores orientaram os novatos a utilizarem a internet uma hora por dia. Consequentemente, após esse período, os novos registros mostraram que a área do córtex pré-frontal que antes estava dormente, agora se mostrava em maior atividade, se aproximando aos cérebros dos veteranos. Isso levou a perceber o quanto o cérebro é moldado de acordo com as experiências que o indivíduo vivencia.

Em 2008, durante dois meses, uma companhia israelense chamada Clicktale coletou dados sobre o comportamento de um milhão de visitantes aos sites mantidos pelos seus clientes ao redor do mundo. Descobriu-se que, na maioria dos países, as pessoas despendem, em média, entre 19 e 27 segundos olhando uma página antes de passarem para a próxima, incluindo o tempo para a página carregar na janela do browser" ${ }^{10}$. Este estudo nos mostra que "a internet é, pelo seu design, um sistema de interrupção, uma máquina calibrada para dividir a atenção" (CAAR, 2011, pp. 188-189), e por causa da alta dispersão que ela proporciona, a leitura se torna descuidada, o pensamento se torna apressado

\footnotetext{
${ }^{9}$ O Google surgiu no ano de 1998, como uma empresa privada que visa organizar a informação mundial hospedando e desenvolvendo uma série de serviços e produtos baseados na internet. A empresa oferece softwares de produtividade online, como o e-mail Gmail, e redes sociais, como o Google+ e outros.

${ }^{10}$ Browser é um programa desenvolvido para permitir a navegação pela web, capaz de processar diversas linguagens, como HTML, ASP, PHP. Sua interface vai variar de acordo com a marca, onde quem escolhe é o usuário.
} 


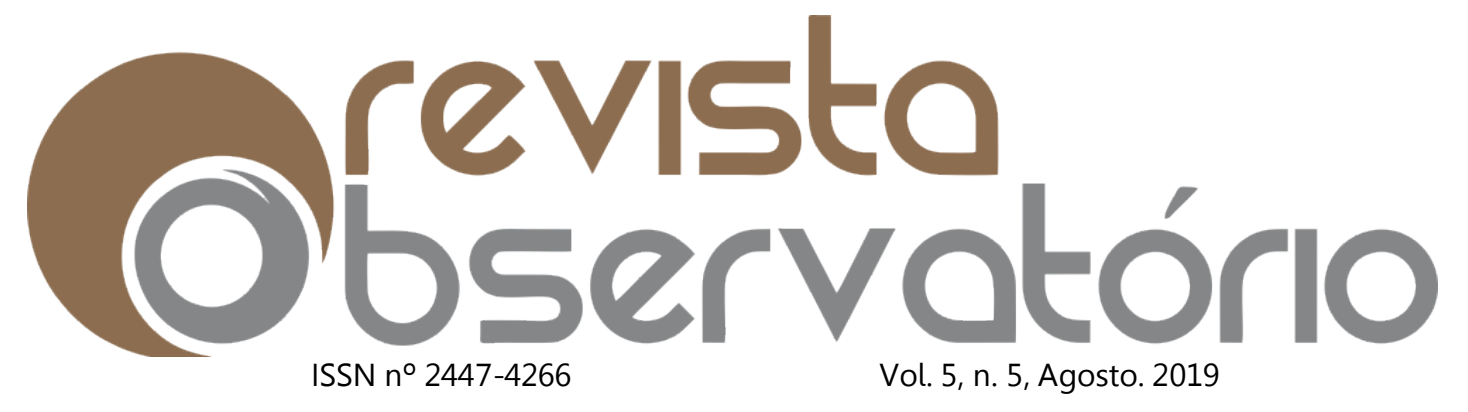

DOI: http://dx.doi.org/10.20873/uft.2447-4266.2019v5n5p983

e distraído, e o aprendizado, superficial. No capítulo 7 de seu livro, Caar (2010) afirma que, ainda que seja possível pensar profundamente enquanto se surfa na internet - da mesma forma em que é possível pensar superficialmente enquanto se lê um livro - não é este o tipo de pensamento que a tecnologia encoraja e recompensa.

O sistema de tecnologia intelectual Google, por exemplo, baseia seus lucros na velocidade em que são consumidas as informações. Quanto mais links e páginas são visitadas, mais oportunidades a companhia tem de coletar informações sobre os usuários e, deste modo, apresentar anúncios a eles. Seu sistema de propaganda é explicitamente projetado para descobrir quais mensagens têm a maior probabilidade de captar a nossa atenção e então colocar essas mensagens no nosso campo de visão. A última coisa que a companhia gostaria de encorajar é a leitura vagarosa ou o pensamento lento e concentrado (CAAR, 2011, p. 214).

No que diz respeito a capacidade de aprender, Caar (2010) vai citar outros estudos que comprovam que nossa capacidade de aprender pode ser severamente comprometida quando nosso cérebro é sobrecarregado com diversos estímulos imagéticos, mas para discorrer sobre este aspecto, gostaria de trazer as contribuições do estudos de Christoph Türcke $(2010)^{11}$, que traz uma interpretação histórica e psicanalítica sob o campo da filosofia, sobre os efeitos na atividade do pensamento no sujeito mergulhado na atualidade tecnodigital. Ao adotar um ponto de vista filogenético desde o paleolítico, esse autor compreende, na esteira de Freud, que as fabulações oníricas constituíram os primórdios da consciência humana. Isso significa dizer que, no princípio, o ser humano conseguia apenas fixar involuntariamente as imagens trêmulas no cérebro e, assim, captar os sentidos de modo semelhante a um sonho ou um

11 In: TURCKE, Christoph. Filosofia do Sonho. ljuí: Unijuí, 2010a.

Revista Observatório, Palmas, v. 5, n. 5, p. 983-998, ago. 2019 


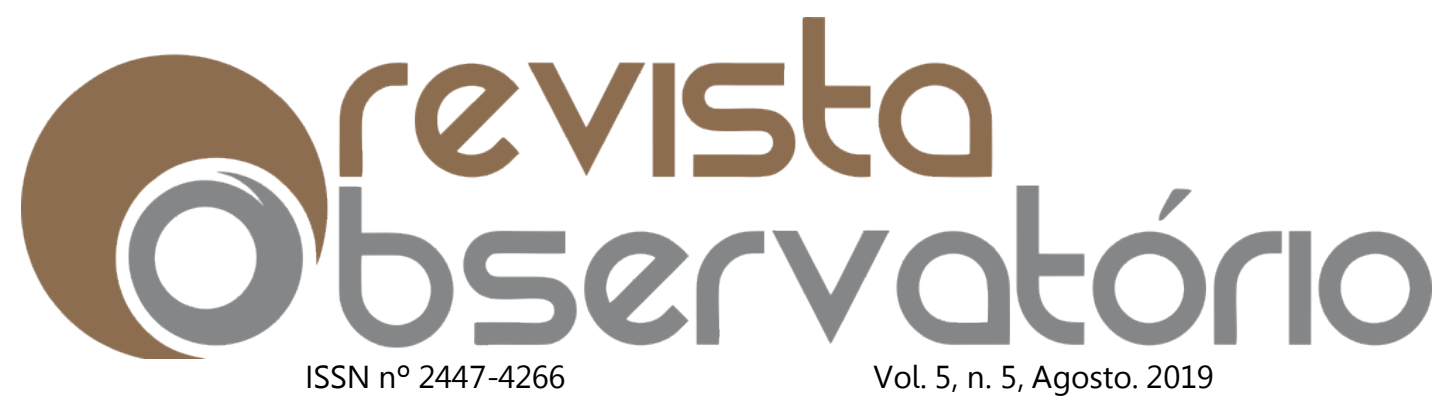

DOI: http://dx.doi.org/10.20873/uft.2447-4266.2019v5n5p983

delírio. Foi somente com o passar do tempo que ele foi adquirindo a capacidade de consciência e razão tal como nós as experimentamos hoje. Türcke (2010a) considera que a atividade do pensamento deve ser compreendida sob à luz da teoria psicanalítica que traz para as fabulações oníricas um lugar de destaque neste processo. Freud afirma $(1900)^{12}$ que os sonhos se deixam reger por processos primitivos primários, aliado ao princípio de prazer ${ }^{13}$. Já o pensamento racional seria regido pelo "processo secundário" envolvendo o raciocínio lógico e as representações devidamente coordenadas em nível da consciência, em acordo com o chamado "princípio de realidade"14.

Ainda de acordo com Freud (1900), seria por meio de três mecanismos básicos que $\mathrm{o}$ indivíduo chegaria a produzir as fabulações oníricas: a condensação, o deslocamento e a inversão. Estes três mecanismos norteiam, sob a forma de noções conceituais, a abordagem filosófica de Türcke para pensar o fenômeno da consciência, e, consequentemente, da linguagem. Dessa forma, o surgimento de ambas teria se desenvolvido originalmente no homo sapiens mediante certo controle bem sucedido de seus impulsos mais primitivos. Durante um longo período que compreendeu milhares de anos, o estado de consciência humana teria, enfim, se estabelecido pelo recalque daquele tipo de pensamento mais primitivo e delirante. A noção de recalque é utilizada por Türcke para designar um processo em que o chamado inconsciente - sede dos processos primários tal como apontados por Freud - foi sendo transformado,

\footnotetext{
12 In: FREUD, Sigmund. (1900). A interpretação dos sonhos. Edição Standard Brasileira das Obras Psicológicas Completas de Sigmund Freud. Rio de Janeiro: Imago, 1969.

${ }^{13} \mathrm{Na}$ teoria psicanalítica da personalidade de Freud, o princípio do prazeré a força motriz do id, que busca a satisfação imediata das pulsões, desejos e impulsos mais primitivos.

${ }^{14} \mathrm{O}$ princípio de realidade é primeiramente enunciado na obra do Freud, em Formulações sobre os dois princípios do funcionamento mental (1911), como uma espécie de evolução do funcionamento psíquico, em que o princípio de realidade realiza-se ao nível da pulsão de autoobservação.
} 


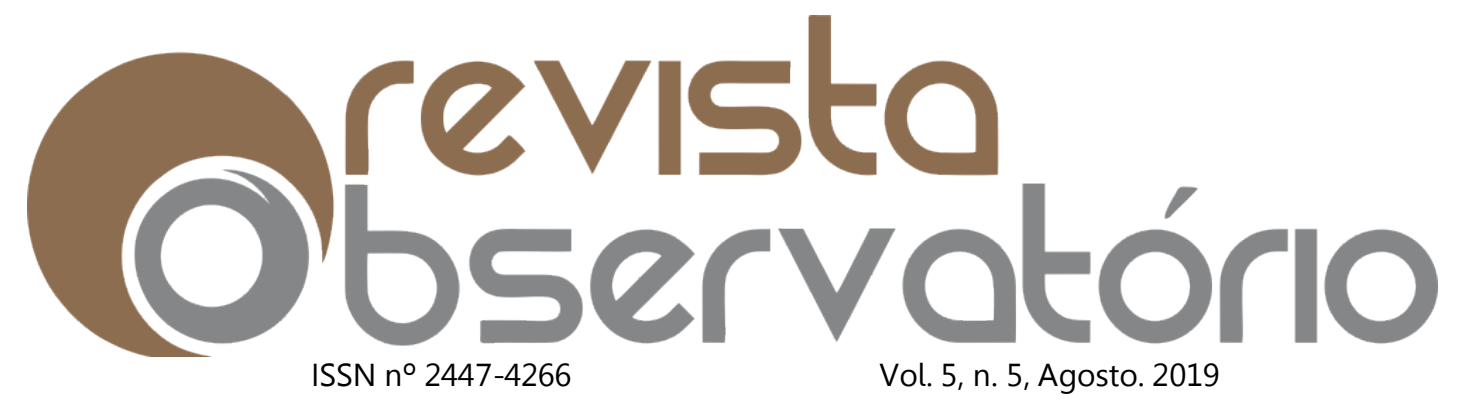

DOI: http://dx.doi.org/10.20873/uft.2447-4266.2019v5n5p983

paulatinamente, em consciência, enquanto um conjunto de representações coordenadas logicamente de modo relativamente estável. Destarte, o autor defende que se o estado de cultura high tech atual nos remetesse novamente aos primórdios de nossa própria humanidade. Algo como o "retorno do recalcado ${ }^{15 "}$ em termos filogenéticos, aludindo a Freud. Ou seja, assim como na era paleolítica, o delírio foi recalcado pela atividade consciente dando passagem ao pensamento e à linguagem, hoje nos encontramos na posição inversa: o sonho está se dissociando, se misturando com o pensamento desperto. $E$, com isso, o descanso mental também se transformaria em inquietação mental fazendo com que o pensamento retroceda às imagens a partir das quais se desenvolveu.

Seguindo a trilha aberta por Horkheimer e Adorno $(1985)^{16}$, seria por intermédio do sentimento de medo e estranhamento que o ser humano passou a dominar os fenômenos do mundo circundante - vale dizer: os fenômenos da natureza externa e também interna. Türcke (2010b), por seu turno, toma a invenção da fotografia e do cinema como um marco de ruptura entre o processo de desenvolvimento e de sedimentação da consciência humana desde os tempos arcaicos e como o início de uma nova "cultura imagética". É como se o click da máquina conseguisse captar e condensar uma memória arcaica, remetendo o homem aos primeiros choques vivenciando na pré-história e, ao mesmo tempo, o preparasse para um futuro superabundante de estímulos, virtualidade e choques imagéticos permanentes. Para Türcke, a compulsão sobre a repetição das imagens, fenômeno tão característico da cultura atual, ainda recobriria o expediente de fuga original causado por aquele choque mais primitivo

\footnotetext{
15 O retorno do recalcado é um conceito da psicanálise que descreve um processo psíquico em que representantes pulsionais são expulsos da consciência e, posteriormente, retornam de maneira distorcida ou deformada.

16 In: ADORNO, Theodor W; HORKHEIMER, Max. Dialética do Esclarecimento. Trad. Guido Antonio de Almeida. Rio de Janeiro: Ed. Jorge Zahar, 1985.
} 


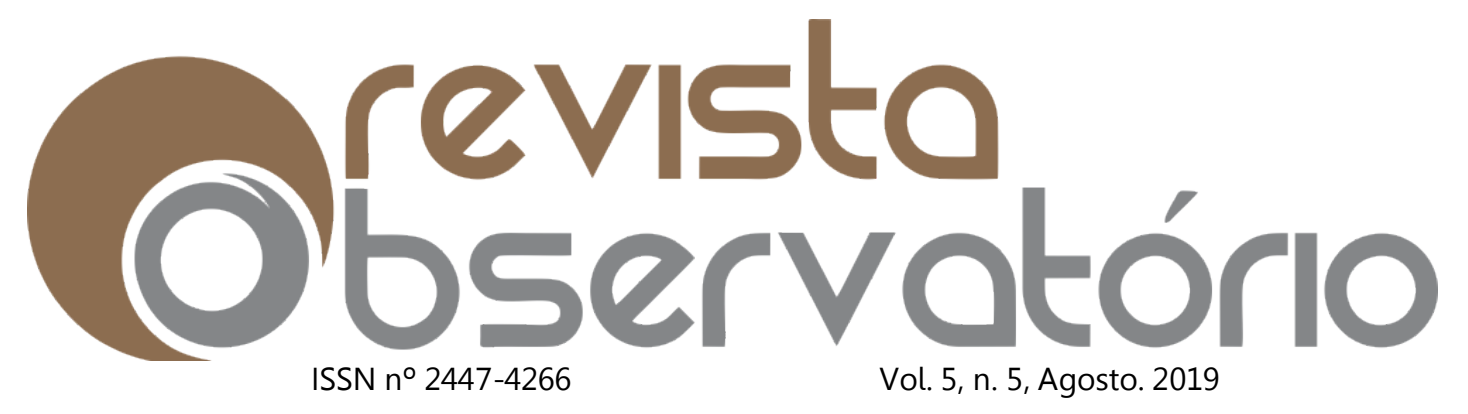

DOI: http://dx.doi.org/10.20873/uft.2447-4266.2019v5n5p983

ocasionado na passagem da inconsciência para o processo de consciência, que de algum modo representa escapar pelo choque do terrificante ocasionado por uma natureza hostil.

Para Türcke (2010) a intensidade destes choques acarretam no desenvolvimento de um sistema nervoso dependente e viciado em sensações. É como se o excitamento imagético contínuo produzisse um efeito semelhante ao vício das drogas. Türcke teme que a hiperinflação desses choques imagéticos possa alterar de maneira drástica a capacidade de assimilação, linguagem e reflexão consciente. O autor acredita que devido à exposição incessante às torrentes de imagens, a própria função do sonho - elaborar os restos diurnos possa dar passagem a um estado de agitação patológica e doentia. O sonho, segundo a definição de Freud, seria o "guardião do sono"; cuja função seria inverter palavra em imagem para se obter um descanso mental. Seguindo a abordagem do autor, a funcionalidade do sonho estaria se desfazendo na medida em que nossa sociedade tem vivenciado o estado de sonho em vigília, transformando os fluxos sintáticos de palavras em fluxos de imagem. As novas maneiras cibernéticas de linguagem, expõe uma gradativa substituição das palavras por animações e ícones que traduzem sentimentos e situações, ao mesmo tempo em que as abreviações vão fazendo cada vez mais parte da cultura escrita. A partir do aval da sociedade é como se as fabulações oníricas saltassem da subjetividade para o mundo objetivo; tornarem-se "reais" e ao mesmo tempo, "virtuais", sendo que as possibilidades vivenciadas em termos virtuais, muitas vezes são muito mais atraentes do que as experimentadas em termos de realidade.

Türcke (2010), compreende o virtual como força ou possibilidade para o existente. $E$, por se tratar de possibilidade, pode-se dizer que a virtualidade já possui um certo grau de realidade e consciência. $\mathrm{O}$ autor afirma que as imagens 


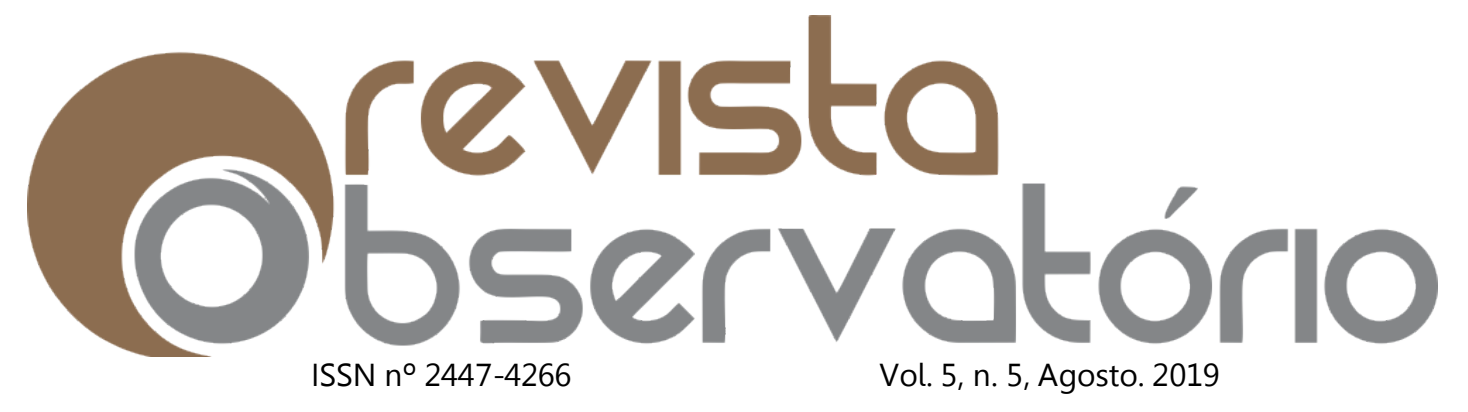

DOI: http://dx.doi.org/10.20873/uft.2447-4266.2019v5n5p983

virtuais assumem a forma de pré-prazer, tal como desenvolvido por Freud. Ou seja, uma expectativa capaz de gerar uma satisfação substitutiva à satisfação terminal. As tecnologias digitais seriam, assim, máquinas pré-prazerosas avançadas que possuem todos os recursos de um substituto do prazer para o qual o pré-prazer apenas incita. Porém, de acordo com Freud $(1905)^{17}$, se contentar com o pré-prazer ao invés do prazer, seria realizar uma inversão de caminho, seria como trilhar o caminho da perversão. Por isso, para Türcke (2010), a sensação de proximidade e de imediaticidade instituída pelas máquinas, como forma de superação de espaço e tempo, de forma alguma pode ser confundida com a aproximação humana, pois esta deve ser construída a partir do convívio mútuo, da atenção, da troca e da identificação acompanhada de certa dose de frustração. E para isso, é necessário exatamente aquilo que as tecnologias desejam economizar ao máximo: o tempo. O mesmo acontece com a comunicação pela internet: ela foi intensificada e acelerada, porém a proximidade obtida permanece na condição de sucedâneo. Neste sentido, substituir de maneira intensa o virtual pelo real, transformando-o em algo primário, "é o mesmo que se desabituar de comer, pois viver de brisa é muito mais excitante" (TURCKE, 2010, p. 291).

Por conseguinte, diante do olhar filosófico e psicanalítico da subjetividade apresentado por Türcke (2010), junto a percepção sociológica de Hall (2006) que traz uma dimensão de identidade pós-moderna fragmentada, incompleta e contraditória, e, ainda, os estudos neurocientíficos de Caar (2011) que apresentam resultados empíricos das alterações cerebrais resultantes da sociedade em rede, seguiremos agora no sentido de pensar uma perspectiva educacional que consiga superar a tendência tecno-mercadológica - que inclui

\footnotetext{
${ }^{17}$ FREUD, Sigmund. (1905). Três ensaios sobre a teoria da sexualidade. Edição Standard Brasileira das Obras Psicológicas Completas de Sigmund Freud. Rio de Janeiro: Imago, 1969.
}

Revista Observatório, Palmas, v. 5, n. 5, p. 983-998, ago. 2019 


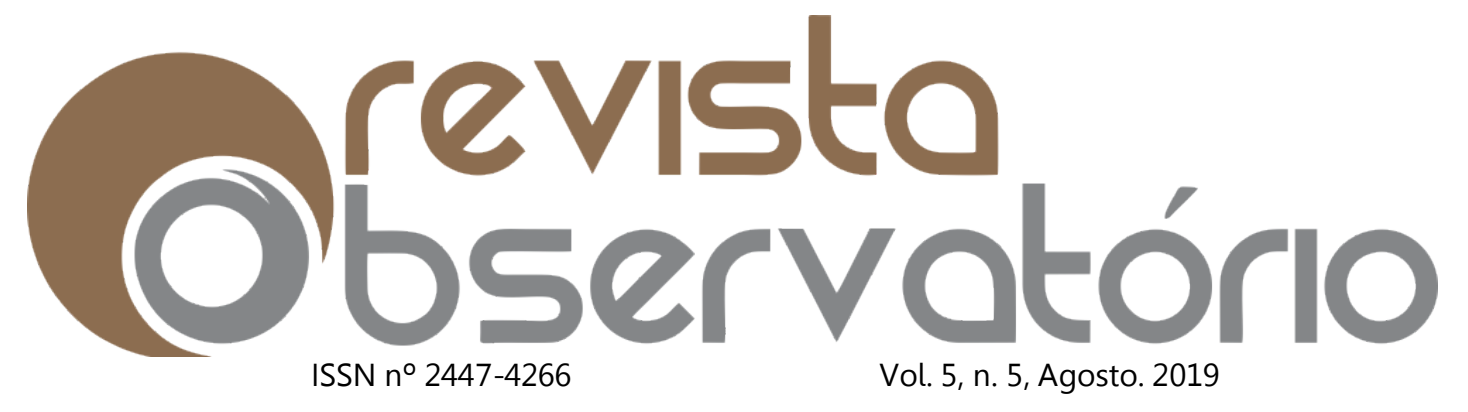

DOI: http://dx.doi.org/10.20873/uft.2447-4266.2019v5n5p983

todo este congestionamento visual que se utiliza da fotografia, do cinema, da internet, da televisão e da propaganda para transmitir uma ideologia de diferenciação baseada na concorrência e na imagem - para que se possa garantir uma prática reflexiva e crítica do pensamento por meio da concentração e do resgate da experiência que tem sido constantemente fragmentada e inundada pelo choque imagético e informacional.

Para Chaui ${ }^{18}$, formação significa promover uma relação com o tempo, ou seja, introduzir no aluno, o passado de sua cultura, despertando-o para questões que este passado engendra no presente (2003, p.12). Já para os filósofos alemães, em especial Theodor W. Adorno, o conceito de formação passa pela noção de Bildung, em que o termo trata de um processo de aprendizagem educacional e cultural na esfera subjetiva e prática na qual a apropriação do objeto se dá pela experiência e pela práxis. Contrapondo-se à condição social de adaptação e conformismo à qual o sujeito está submetido, Adorno revela que a essência da experiência formativa consiste na compreensão do presente como histórico e na recusa de um curso pré-traçado da história. Nestes termos, seria por meio do confronto com a sua própria limitação, que o indivíduo desenvolveria uma crítica ao existente pela via da apreensão de suas contradições e da resistência. No ensaio "O que significa elaborar o passado", que se encontra no livro Educação $e$ Emancipação (1995), Adorno sustenta que a racionalidade instrumental da sociedade industrial estaria liquidando os elementos perturbadores do tempo e da memória. Por meio da crítica sobre as formas como a sociedade alemã pósnazista enfrentava o seu passado, ele alerta que o esquecimento é desejável por aqueles que cometeram injustiças.

Já para o

18 In: CHAUÍ, Marilena. As manifestações de junho de 2013 em São Paulo. In: Revista Teoria e Debate, 26 de junho de 2013. 


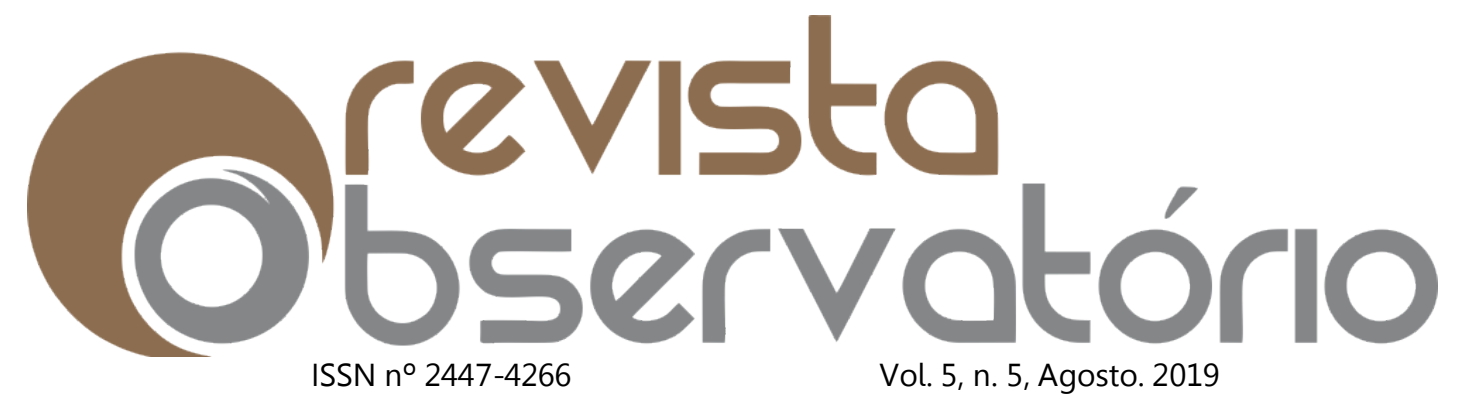

DOI: http://dx.doi.org/10.20873/uft.2447-4266.2019v5n5p983

pedagogo brasileiro Saviani (1988), o trabalho educativo é (ou deveria ser) o ato de produzir direta e intencionalmente, em cada indivíduo singular, a humanidade que é produzida histórica e coletivamente pelo conjunto dos homens. Neste sentido, a escola deveria oportunizar a crítica dos saberes, valores e práticas da sociedade. Esta afirmação impõe um grande desafio, na medida em que as circunstâncias contemporâneas submete o indivíduo a um contínuo processo de fragmentação e saturação informacional que os impede de pensar e agir.

As tecnologias digitais em prol da reprodução do capital permitem a aceitação de uma realidade destorcida, sem que seja tecido nenhum tipo de questionamento sobre ela.

Por isso, o primeiro passo para se pensar uma nova abordagem digital no contexto escolar, é reconhecer os efeitos que a velocidade e intensidade dos fluxos virtuais atuais (à favor desta lógica) evidenciam em termos de identidade e subjetividade para que em seguida seja possível superar a crítica, por meio de ações pedagógicas conscientes que se utilizem destes recursos a favor de um reconhecimento mais amplo sobre o processo civilizatório, social e político ao qual o indivíduo contemporâneo encontra-se situado.

Para Sibilia, o empobrecimento da linguagem, como argumentado por Turcke, apenas contribui para um vazio sem elaboração consciente "quando a opinião substitui o pensamento e a informação ocupa o lugar do saber e do conhecimento" (2012, p. 86). Na esteira desta afirmação, finalizaremos este artigo trazendo a linguagem mitológica, que em sua riqueza simbólica nos convoca para uma perspectiva temporal e do conhecimento que conecta nossa experiência ao passado, drasticamente esquecido pela lógica da superficialidade e da instantaneidade. A alegoria da caverna, descrita no livro A República (1999) de Platão fala de um local em que pessoas nascem e vivem acorrentadas de costas para a entrada, de modo que não conseguem se mexer e nem enxergar 


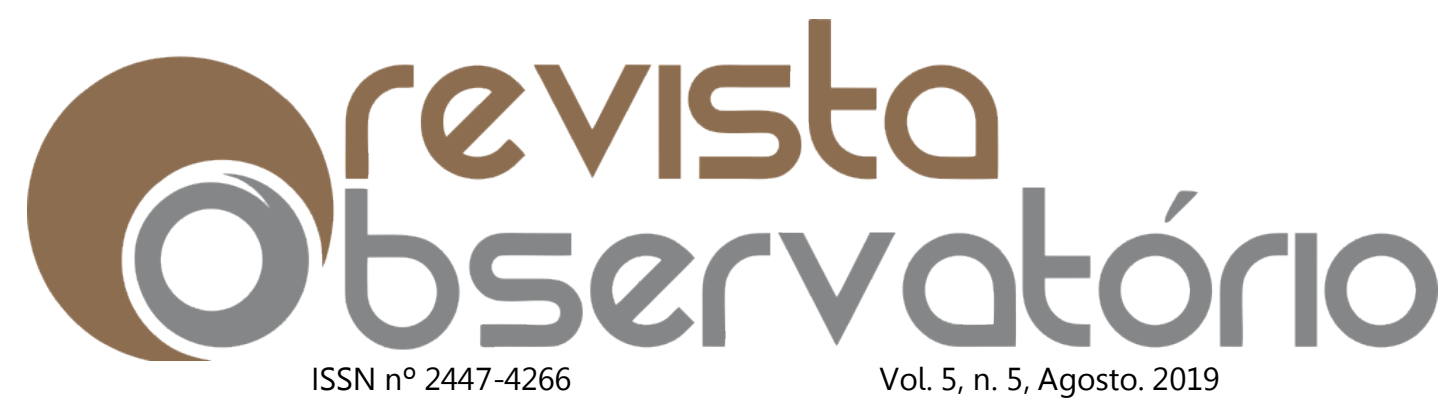

DOI: http://dx.doi.org/10.20873/uft.2447-4266.2019v5n5p983

nada além da parede do fundo que é iluminada pela luz gerada por uma fogueira. Nessa parede são projetadas sombras de estátuas representando pessoas, animais, plantas e objetos, mostrando cenas e situações do dia-a-dia. Os prisioneiros dão nomes às imagens (sombras), analisando e julgando as situações.

Platão (1999, p. 225) afirma que estas sombras seriam de outras pessoas, objetos e animais que viviam fora da caverna e, que projetados para dentro daquele "mundo", eram vistas como formas verdadeiras em vez de sombras; uma vez que essa era a única realidade que conheciam. Assim, essas sombras passavam a ser confundidas com a própria realidade e com a verdade, ou seja, ocorria uma confusão entre o ser e o não ser. Apesar de ser apenas uma projeção do mundo real e uma distorção da realidade, as pessoas que estavam lá dentro não eram capazes de imaginar outra realidade. Nesse mito exposto por Platão (1999), somente quando um dos prisioneiros se libertasse da caverna, enfrentando primeiramente a luz do sol, ele então passaria de fato a enxergar e conhecer a forma como as pessoas, animais e objetos eram de verdade.

Contudo, ainda segundo Platão (1999), se este prisioneiro que se libertou voltasse para a caverna e contasse o que viu do lado de fora aos demais, seria taxado como louco e acabaria sendo morto pelos habitantes da caverna, que não aceitaram a verdade que estaria por detrás das sombras. Na obra A Caverna, de José Saramago (2000), encontra-se uma releitura da alegoria da caverna de Platão. Saramago argumenta que o que fora retratado muitos anos antes de Cristo pelo filósofo grego se apresenta nos dias atuais de maneira ainda mais intensa, pois as imagens que nos mostram substituem a realidade em si, invertendo valores e alienando as pessoas. A maioria das imagens que são vistas pelos indivíduos não lhes tenta falar algo, mas vender algo. E, o espetáculo que 


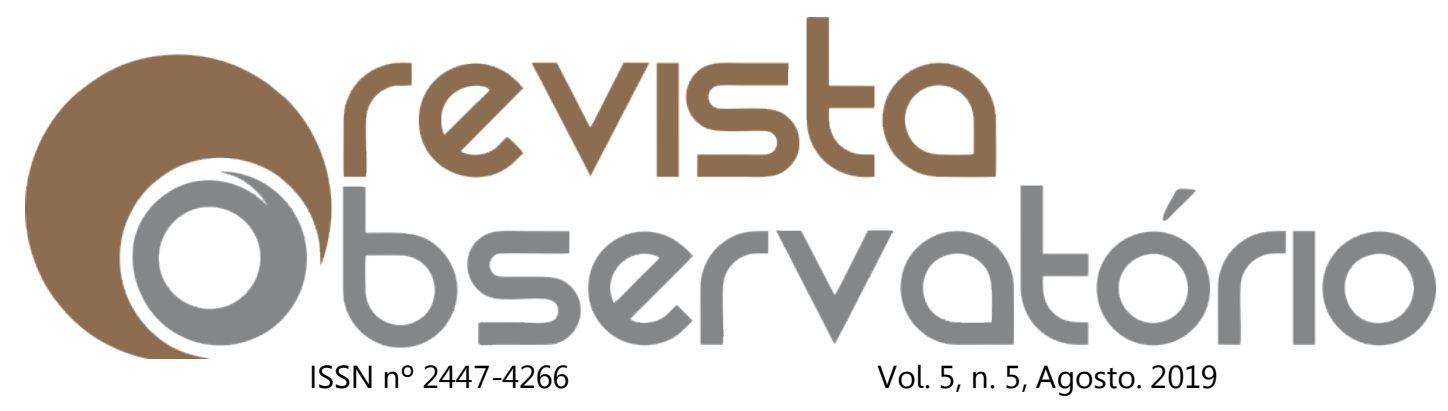

DOI: http://dx.doi.org/10.20873/uft.2447-4266.2019v5n5p983

o mundo oferece ao homem é o mundo da desigualdade.

Portanto, entendendo que essa caverna apresenta uma das polaridades dos recursos digitais - que à favor da lógica capitalista e mercadológica produz um encantamento capaz de obstruir de maneira concreta e subjetiva a capacidade de reflexão crítica e histórica das imagens e informações ofertadas concluímos que uma educação que caminhe na direção contrária, deve assumir uma estratégia capaz de se utilizar destes recursos para garantir a fixação do conhecimento através de uma reconexão com um passado que auxilie na crítica e decodificação do caos informacional.

Uma formação a favor da novo modelo de subjetividade, deve ser capaz de superar o sentido etimológico da palavra aluno ${ }^{19}$ em que a condição de viver sem luz ou nas sombras da caverna, enquanto um mero receptor de imagens, se transforme na capacidade de produzir um modo ativo de operações necessárias para fixar e dar sentido a uma experiência individual que reconecta os fragmentos de sua dimensão social e coletiva de ser e estar no mundo. (SIBILIA, 2012, p.87)

\section{REFERÊNCIAS}

ADORNO, Theodor W; HORKHEIMER, Max. Dialética do Esclarecimento. Trad. Guido Antonio de Almeida. Rio de Janeiro: Ed. Jorge Zahar, 1985.

Educação e Emancipação. Rio de Janeiro: Paz e Terra, 1995.

\footnotetext{
${ }^{19}$ O termo latino "lumen", nominativo, e seu genitivo "luminis", cujo significado original é luz acarreta em uma interpretação etimológica da palavra aluno, em que o prefixo "a" tem o sentido de negação ou daquele que se encontra na ausência da luz. Neste sentido, o termo carrega uma perspectiva histórica de um indivíduo desprovido de luz ou que deve ser iluminado.
} 


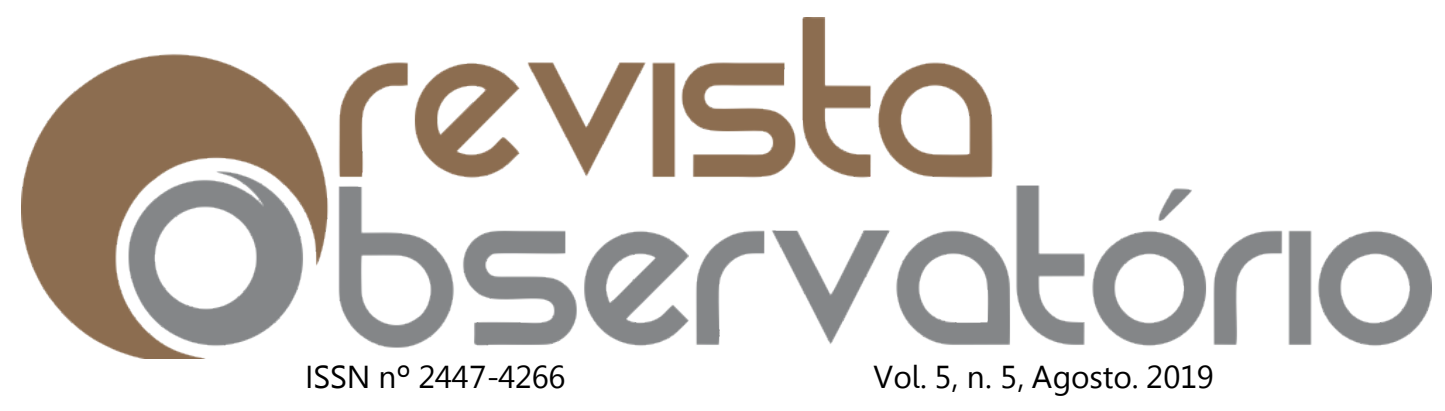

DOI: http://dx.doi.org/10.20873/uft.2447-4266.2019v5n5p983

CAAR, Nicholas. A geração superficial. O que a internet está fazendo com nossos cérebros. Tradução de M. G. F. Friaça. Rio de Janeiro: Ed: Agir, 2011.

CHAUÍ, Marilena. As manifestações de junho de 2013 em São Paulo. In: Revista Teoria e Debate, 26 de junho de 2013.

FREUD, Sigmund. (1900). A interpretação dos sonhos. Edição Standard Brasileira das Obras Psicológicas Completas de Sigmund Freud. Rio de Janeiro: Imago, 1969.

FREUD, Sigmund. (1905). Três ensaios sobre a teoria da sexualidade. Edição Standard Brasileira das Obras Psicológicas Completas de Sigmund Freud. Rio de Janeiro: Imago, 1969.

HALL, S. Identidades Culturais na Pós-Modernidade. Tradução de Tomaz Tadeu da Silva; Guacira Lopes Louro. 11. ed. Rio de Janeiro: DP\&A, 2006. KEHL, Maria Rita. A Juventude como Sintoma da Cultura. In: NOVAES, Regina; VANNUCHI, Paulo (Org.). Juventude e Sociedade: trabalho, educação, cultura e participação. São Paulo: Ed. Fundação Perseu Abramo, 2004.

PLATÃO. A República. Trad. Enrico Corvisieri. São Paulo: Abril Cultural, 1999. (Coleção Os Pensadores).

SARAMAGO, José. A caverna. São Paulo: Companhia das Letras, 2000.

SAVIANI, Demerval. Escola e Democracia. São Paulo: Cortez, 1988.

SIBILIA, Paula. Redes ou Paredes: A escola em tempos de dispersão. Ed.Contraponto. Rio de Janeiro, 2012.

TURCKE, Christoph. Filosofia do Sonho. ljuí: Unijuí, 2010a.

Sociedade excitada. Campinas: Ed. Unicamp, 2010b.

. Entrevista Revista Filosofia. Portal Ciência e vida. Disponível em: http://psiquecienciaevida.uol.com.br/ESFI/Edicoes/53/artigo192215-1.asp>. Acesso em: 15 de dezembro de 2013 